\title{
Empowering the next generation: Girls of the Maqattam garbage settlement
}

Marie Assaad

Judith Bruce

Population Council

Follow this and additional works at: https://knowledgecommons.popcouncil.org/departments_sbsr-pgy

Part of the Family, Life Course, and Society Commons, Inequality and Stratification Commons, International Public Health Commons, and the Labor Economics Commons How does access to this work benefit you? Let us know!

\section{Recommended Citation}

Assaad, Marie and Judith Bruce. 1997. "Empowering the next generation: Girls of the Maqattam garbage settlement," SEEDS no. 19. New York: Population Council. 


\title{
EMPOWERING THE NEXT GENERATION: GIRLS OF THE MAQATTAM GARBAGE SETTLEMENT
}

\author{
by Marie Assaad and Judith Bruce
}

\section{Introduction}

This edition of SEEDS explores the parallel challenge of extending earning opportunities and access to valued social roles to young women--that is adolescent girls twelve to twenty years of age living in a highly traditional, marginalized, and impoverished community on the outskirts of Cairo, Egypt. Apart from its focus on adolescents, this edition is distinctive in another way as it underscores the degree to which livelihood programs must confront the social circumstances-such as health, marriage, and cultural and family traditions--that play a major role in shaping girls' current and future economic prospects. It follows in a SEEDS series that has not only dealt with income-generation and livelihood opportunities for adult women but has detailed the organizational/institutional/community mechanisms (such as the provision of child care or the creation of cooperatives) necessary to enable women to overcome social resistance to their control over their own labor, income, and access to the job market.

To date, proposals to increase adolescent girls' training for or participation in meaningful livelihoods have been largely absent from the current policy debate over adolescents, which is often centered narrowly on fertility; and the scarcity of effective income-generation programs for this age group does not enhance the policy discussion. This edition of SEEDS, therefore, should be of broad value to those seeking to increase girls' autonomy, and as a result their well-being, in terms of their future productive and reproductive lives.

Recently, a group of adult leaders of youth programs around the world were asked to list what they considered to be the most important issues for adolescents. [1] Forty percent of those from Africa identified employment as key, yet only four percent of the adolescent programs in that region indicated that they were directed toward skills training and employment creation. This is largely because when girls are identified as the subject of gender-specific strategies, the focus is most often on nonformal education, nutrition, reproductive health, and a search for means to delay marriage and childbearing. The experience documented here suggests that microenterprise should be considered more seriously, alongside these other useful interventions, as an entry point for changing the social terms of reference for adolescent girls. The experience of working as a team to produce goods for sale and learning how to manage income of their own can impart important decision-making skills that assist girls not only in negotiating for their livelihoods, but also for reproductive health and choice over the longer term.

Up until now in Egyptian society, as in many parts of the world, girls-from the point when their schooling ends to the moment when marriage becomes a socially accepted and legal realityexist in a social void. However, in the Maqattam garbage settlement (where this story is set), the situation is changing as a unique intervention has begun to define alternative expectations and opportunities for adolescent girls, providing them with a bridge between childhood and the onset of marriage and childbearing. The Association for the Protection of the Environment (APE), the focal development project operating in the Maqattam community, has singled out young women for special efforts because program organizers view girls' social and economic development as inextricably linked with community betterment. By giving young women the skills and self-esteem 
they need to be able to participate more meaningfully in community life, and the labor market, they are seeding a wider revolution.

\section{Life in a Garbage Village}

Maqattam is a settlement of 17,000 people whose livelihoods are directly or indirectly linked to the collection and sorting of garbage. The garbage settlements of Cairo-of which Maqattam is the largest-were established on the outskirts of the city in the 1940s by landless peasants migrating from Upper Egypt. Here extended family groups adapted their rural skills to create an urban livelihood by meeting the metropolis's need to dispose of ever-increasing amounts of waste materials. The current Maqattam settlement was founded in the 1970s as, with Cairo's rapid growth, earlier settlements of Zabbaleen (garbage collectors) were evicted from the center city. Though the site of the garbage collection villages has shifted over time, the methods of collection have remained remarkably consistent for most of the last 50 years. From just after midnight until the break of dawn, family-owned donkey carts moved along routes allocated to them by middlemen. Traditionally, adult male members of the family collected the garbage, bringing younger children (both male and female) along to sit on the donkey carts and guard the collected garbage. Today, this system is undergoing a slow process of modernization and regulation. In the late 1970s, the government decreed that donkey carts would no longer be acceptable for garbage collection and banned them from the entire city. According to a 1993 survey, 84 percent of garbage-collecting families now use trucks to service their collection routes. Some own their trucks, while others lease vehicles. But many families continue to use donkey carts "illegally" in areas that are less well patrolled. [2]

Over the last 15 years, both the value placed on garbage removal and the potential uses of recyclable material have increased. In the past, the most profitable element of the sorted garbage was the food, used for raising animals, and waste paper which could be resold. Very gradually, other items have entered the list of recyclables for which there is now a more organized market. Maqattam today is a substantially more diversified community economically than it was in the late 1970 s or even in the early 1980s when almost all families did some garbage collection and kept pigs as their primary biological recycling agents. The economy of Maqattam has modernized, grown (in terms of economic yield) and, although still concentrated on garbage-related activities, diversified. A 1993 survey found that nearly half of households continue to collect garbage while another 15 percent do other productive work linked to solid waste management.

When the carts and trucks return to Maqattam each day, the garbage is dumped directly into the center of the family home. Family members quickly make crude divisions of recyclables, separating out paper, glass, clothes, and bones. This is an overwhelmingly arduous and unpleasant task that for the most part belongs to women and girls who spend many hours every day separating garbage. Animal bones are set aside to be collected by middlemen who sell them to make glue; organic material is fed to the pigs which many families still keep. (The majority but not all the families in the garbage village are Coptic Christians who, unlike Muslims, have no social taboos against raising and eating pigs.) The sale of pigs still provides a major portion of the income of garbage-collecting families.

The next level of recycling is conducted by enterprises which are often run by other Maqattam families. For example, some families recycle plastic by cutting it manually with industrial scissors and selling it in bulk. Others families wash and sort plastic bags by color and density before 
sending them to the plastic shredders, or they package and bale little bits of paper and flatten and tie up cardboard in bunches of 50 and 100 for resale.

Beginning in the early 1980s, the Zabbaleen settlement of Maqattam became the focus of a large-scale community upgrading initiative. This included support received under the First Egypt Urban Development Project, formulated in 1976 by the Egyptian government and the World Bank. Since then there have been many actors and numerous sponsors, however, the role of Environmental Quality International (EQI) bears special mention. EQI is a consulting firm specializing in solid waste management and urban upgrading. Directed by Dr. Mounir Nenatalla, EQI's development professionals have carried out in-depth studies of both living conditions and economic prospects of the Maqattam community. Many of the facts and figures reported in this edition of SEEDS emanate from EQI's baseline and intervention studies.

Development work in Maqattam has always been characterized by a high degree of collaboration. In terms of funding, various upgrading and social development schemes have been supported by: the World Bank, the Ford Foundation, Oxfam, Catholic Relief Services, the Soeur Emmanuel Fund, and the European Community.

In 1984, the APE was officially registered with the Ministry of Social Affairs as a nongovernmental organization responsible for managing a composting plant in Maqattam and initiating various social development activities in the community. The APE's board members are selected for their expertise (in areas such as finance, social development, and environmental sciences) as well as their caring concern for the citizens of Maqattam. Over the years, an increasing proportion of board members are being drawn from among the volunteers and staff who work in the Maqattam development scheme.

The APE is a secular organization in which both Copts (Christians) and Muslims participate. In 1987, the APE board authorized the creation of a human development component within the organization to carry out a variety of aims stipulated in the APE's constitution. Many of the activities reported here are currently managed by the Health and Development Committee (officially constituted as an APE subcommittee in 1990), which coordinates activities in the areas of health, functional literacy, and income-generation. [3]

The project's founders--professionals with skills in environmental sanitation as well as economic and social development-were motivated by two main goals. First, they were seeking to relieve the unhealthy and socially degrading living circumstances of the Maqattam residents. Second, drawing on the potential wealth that the garbage of fourteen million Cairenes might generate, they sought to assist the Zabbaleen to achieve higher productivity from the traditional recycling process. The APE has been very successful in reaching a high proportion of households overall. Today, 70 percent of garbage-collecting households are engaged in one or more activities sponsored by the APE and its affiliate organizations, and a third of all households are directly benefiting from APE-supported activities.

\section{Supporting Girls in Their Transition to Womanhood}

From the beginning, development efforts in Maqattam have given an unusual degree of attention to young people. Indeed, "the social condition of sons and daughters of garbage collectors" was identified as an important target in the APE's original charter. Though boys and girls are both afforded new learning opportunities, the most innovative efforts have been those directed at the 
girls. Improving the degraded status, and tapping the latent capacity of these young women, continues to be a major challenge for the organization.

Close to half of all Maqattam households (garbage collecting and non-garbage collecting alike) have a girl in the household between the ages of twelve and twenty. Laila Kamel, a leader of the APE's rug weaving and patchwork project established for girls, and currently the president of the APE, observes: "Unmarried daughters are constantly under surveillance by their brothers' wives to make sure they do not escape in sharing in the household production activities, whether they are sorting garbage manually, feeding the pigs, heading the household chores, caring for siblings, or fetching water. In general they are shouldering the heavy burden of daily living in an urban slum in Cairo that operates like a typical village in Upper Egypt." [4]

Kamel's observation is important because, though the residents of Maqattam are nominally urban, their notions of appropriate behavior for girls are definitively conservative and rural. This conservatism, combined with the poverty and low social standing of garbage collectors within Egyptian society, serves to make the girls of Maqattam among the most vulnerable groups in Cairo.

As is still the case in rural Upper Egypt, as girls in Maqattam approach menarche their emerging sexual capacity poses a significant risk, both to them as individuals and to their family's status within the community; therefore, their behavior comes under much closer scrutiny. [5] In many cases they now face greater restraints than their younger sisters in terms of mobility and accepted behavior. This relative social confinement, however, does not diminish the demands for their labor. Adolescent girls still make vital and often physically onerous economic contributions to their families every day.

Therefore, it is not surprising that many Maqattam girls complain of constant headaches, fatigue, and dizziness. A study of 60 randomly selected girls showed that 50 to 60 percent had belowaverage hemoglobin levels, and that many also suffered from parasitic disease and infections [6]

Given these health profiles, combined with their low social status and high productivity roles, the APE sought ways to provide support for these girls while, at the same time, capturing their labor for their own benefit, as well as that of their families.

Though universal schooling to age fifteen has been mandated for some time in Egypt, only 82 percent of girls of primary school age (six to ten) actually attend classes, and an even lower proportion (45 percent) attends secondary school. In 1993, only 56 percent of girls age six to nineteen in Maqattam had been enrolled in school at one time or another and of these, 70 percent were still in school while 27 percent had dropped out. Only 1.5 percent of girls had obtained a secondary school certificate or equivalent degree.

Egypt has a rather strict and inflexible school system. Any child not enrolled in school by age eight in effect forfeits her/his right to formal education. The propensity of children to be enrolled in school is linked both to their gender and to the work requirements of their families. Among the Zabbaleen, 44 percent of children six to eleven are defined as "working," as compared to 11 percent of children in all greater Cairo households; 22 percent of all children in the community reportedly combine work and schooling. At older ages, school participation falls dramatically while, for most, work increases. Among youngsters age twelve to fourteen, 66 percent of boys and 59 percent of girls are classified as working; 88 percent of Maqattam's working girls identify their economic activity as garbage collection and sorting. Given the rigidity and limits of the formal 
schooling system, the only route to literacy and numeracy for these out-of-school youth must come through community-based literacy programs sponsored by nongovernmental organizations. [7]

In addition to the pressure to work--particularly intense for girls in garbage-collecting families--the pressure to marry girls off early also limits their schooling. As girls approach menarche, their social acceptability and marriageability, rather than their skills or rights, dominate family concerns. In Maqattam, as in much of Egypt, a respected womanly identity is conferred almost exclusively through marriage. Though the legal age for marriage in Egypt remains at sixteen (with some political pressure to raise it), there is evidence that substantial numbers of girls are married before this age, often with the connivance of the girl's family, the authorities, lawyers, doctors, and religious figures who approve the marriage despite their knowing that the girl is under age. The traditional value placed on virginity is reflected in a variety of customary practices: "virginity tests" can entail a young bride being manually probed by a midwife or the even more traumatic public display of a bloodied sheet on her wedding night.

Not only is underage marriage a violation of girls' human rights, it has long-term negative effects on their physical and emotional well-being. The quality of a girl's marriage will influence both her dignity and her autonomy within that marriage, including her ability to work outside the home and make subsequent reproductive choices. In some cases--given the young age at which childbearing begins--the girls also face elevated reproductive risk. In addition, the younger the girl at marriage, the greater the possibility that she is being married to someone she has not chosen and someone who is potentially much older. (The median age differential in some communities is as high as seven to ten years.)

In rural Egypt, the transition from girlhood to womanhood traditionally has been brief and full of restrictions and hardships. To change this reality for the girls in Maqattam and other such communities obviously requires more than a single intervention--but what is the first step? The earliest social development efforts in Maqattam were initiated by Soeur Emmanuelle, who founded a primary school, and Father Saman, who built a Coptic church which served as a center for social welfare activities. In the early 1980 s, another school was built as part of a World Bank upgrading project, and a children's library and other services were added by the Integrated Care Society under the auspices of Suzanne Mubarak, wife of the Egyptian president. But despite the availability of schooling in the community, many girls were--and still are--withheld from enrollment or are removed from school to fulfill an economic role within their families. The APE, therefore, understood that increasing the prospects of young girls and preparing them for productive adulthood would require more than their participation in formal schooling. As a result, it has adopted a holistic approach that seeks to give the girls a distinct and proud social identity while, at the same time, preparing them for productive livelihoods.

\section{Increasing the Productivity and Safety of Traditional Economic Activities of Girls and Women in Maqattam}

Girls and women in Egypt's garbage-collecting communities make all the usual traditional female contributions to family life: preparation of food, cleaning, maintenance of the household, providing care and nurturing for the dependent young and old, offering rudimentary health care, and, even in this nominally urban environment, food production. Most households keep goats, pigs, and chickens (vital additions to their poor diet), and these animals are all under the supervision of the women. In addition to these already demanding household responsibilities, women and girls in Maqattam are also in charge of most of the family's post-garbage collection tasks, from sorting waste materials to pig-keeping. 
As noted above, every day the collected garbage is dumped and sorted in the midst of the family home where, in many cases, the family also eats, sleeps, and keeps animals. (In recent years, an increasing proportion of households have been able to separate their sleeping and food preparation areas.) The garbage sorting, which typically absorbs four to six hours a day, is split into two sessions: a longer one after the main morning collection (from 5:00 to 9:00 AM) and a shorter evening sorting (anytime from 4:00 PM to 1:00 AM). The work is carried out in bare feet and garbage is sorted with bare hands. (Despite the recent availability of gloves, most girls and women still eschew them because they feel the gloves slow their work.)

Working knee-deep in garbage, the women and girls must sort the vast volume quickly in order to leave the home free for other family activities. Potential food for the pigs and other animals must be separated as rapidly as possible because the Zabbaleen believe that if it rests too long within the undifferentiated refuse, it will become contaminated or lose some of its food value. Girls and women carry the separated food in large metal tubs to the back of the house where the family pigsty is located. The pigs, excellent recyclers themselves, turn the food into rich manure, and their value should not be underestimated. In a 1993 study, it was found that pig-keeping families averaged 2,700 Egyptian pounds (US \$818) per year in income from the sale of pigs alone. Thus for many families, pig-keeping remains by far and away their largest source of income.

EQI's baseline economic analyses, conducted between 1981 and 1983, revealed that much of the garbage collection, sorting, and recycling processes were not only inefficient, but incurred unnecessary and severe health risks.[8] As a result, a sequence of varied interventions--some large, some small--that deal with various phases in the garbage collection and recycling processes have been carried out. The goal has been to make the processing of garbage safer and more efficient while, at the same time, increasing the rate of economic return to the community.

The composting plant, which was completed in the early 1980s, was the first in a series of small economic revolutions that are still underway in Maqattam. Pig manure--which was previously left at the edge of the houses to be carted away by merchants--is now taken directly to the community compost plant where it is turned into fertilizer thus becoming a vital source of income for the community. Every year, since 1988, the total cubic metric tonnage of compost produced and resold has steadily increased. In 1994, in excess of 34,000 Egyptian pounds (approximately US $\$ 10,000$ ) was realized on compost sales. In addition to covering the operating costs of the plant, this money provides a modest profit which is used to support the staff responsible for overseeing the APE's social development components (functional literacy, health, and incomegenerating initiatives).

It is likely that the value of the composting plant and related recycling activities in Maqattam will continue to grow over the coming years. Currently, Maqattam processes 30 percent of greater Cairo's ever-increasing supply of household garbage. With improved recycling techniques, it is estimated that as much as 90 percent of this refuse can be put to some economically valuable reuse.

However, at the same time, modern packaging as well as the types of products now discarded with household waste have not only increased the amount of garbage, but created additional health risks for the Zabbaleen. Garbage today may contain cadmium, lead, and other heavy metals emanating from batteries and some plastic products as well as fungicides and metal parts. Mixed with organic garbage, these elements create a cross-cont amination which even swift sorting cannot eliminate. Further, disposal of an increasing amount of dangerous material (e.g., broken glass) has made injuries among the Zabbaleen more common. 
For this reason, a pilot project to separate garbage "at its source" has been undertaken. Currently operating in the two lower-middle and middle income Cairo neighborhoods of Manial and Deir-elMalak, over 500 families now separate their organic (wet) and inorganic (dry) garbage before it is collected. Residents are encouraged to participate by young educated garbage collectors who hold monthly meetings and go door to door to solicit community support. This simple measure has resulted in a decrease by more than half in the number of hours required to sort the garbage, thus freeing Maqattam's girls and women to spend their time in other income-generating and training activities.

Family health, as well as the health of the garbage sorters themselves, has also improved. Now there are fewer wounds caused by sharp objects and a substantial reduction in the percentage of heavy metal being measured in the organic compost. Separation at the source also improves the quality of organic waste which means that the pigs grow at a faster rate and are more resistant to disease. There is a hope that this "separation at the source" project will be extended to other parts of Cairo.

Both the composting plant and the separation at the source project are examples of communitywide innovations which not only bring general benefits to the community but also bring special benefits to girls within the context of their traditional roles. However, community efforts to improve girls' livelihoods do not end there; specific efforts have been designed to introduce new skills, new social identities, and new income-generating opportunities for adolescent girls.

\section{Nontraditional Economic Skills for Girls and Money of Their Own}

The first livelihood project established for girls in Maqattam was rug weaving. Begun in 1987, the project has two related objectives: first, adding to girls' economic skills and personal income and, second, finding a way to release them, even temporarily, from the confines of their households and the squalor of sorting garbage by hand. Laila Kamel, the volunteer manager of the rug weaving project reflects that "with their eyes focused on a heap of rotting food for a good few hours each day, their world view was one that needed an infusion of color, cleanliness and hope." [9]

To ensure that the neediest girls would be the first members of the rug-weaving cooperative, a set of evocative questions were devised. First, the girls were asked, "Do you still go out on a garbage route?" If they did, particularly those past puberty, it was an indicator of a high degree of poverty because, by the time the project was established, it had become illegal to bring donkey carts into the city and this prohibition was enforced through fines and harassment. Thus, girls who accompanied their fathers on the donkey carts were put into the position of facing arrests and fines, not to mention distasteful and risky contact with strangers. Girls were also asked, "Do you go out on the streets of Cairo on foot with a sack to forage for plastic in the big municipal bins?" This is considered the "ultimate indicator" of vulnerability, as families who gamble on the safety and honor of their adolescent daughters are deemed to be truly desperate. Girls in this category were given top priority to enter the program.

Today, two groups of twenty girls per year spend four hours each day learning rug-weaving skills for a period of three to six months. (The variability of the training period depends upon the regularity with which the girl can attend training sessions and the rapidity with which she masters the new skills.) Though a schedule of training as well as work hours is established, it is not rigidly enforced. In specific cases a girl's schedule will be negotiated with her family so that she is still 
available for garbage sorting and other domestic duties while participating in the program. This is because the rug-weaving program, as with all of the APE's economic interventions directed at young girls, respects the close link between the girls' economic roles, their social development, and their standing within their family.

The program also seeks to impart to the girls a physical sense of selfesteem. Girls are required to show up for work on time and in a clean dress, often one that is set aside specifically for this work. Their nails are expected to be short and their hair clean and tidy as flies, fleas, and other vermin are common in Maqattam. When the girls enter the training or work facility, they first wash their feet at the entrance; many still do not have shoes so the simple act of walking from home to the facility contaminates their feet. This washing of feet redefines the rug-weaving (and now patchwork and papermaking as well) center as a social space apart and different from the home and the street. It is their "school."

During the training period, which ranges from three to six months, girls receive wages of about 40 Egyptian pounds (US \$11.80) a month. If they are not literate, they are also required to enroll in literacy classes which are run on alternate days or off hours so as not to conflict with their skills training. Once the girls have become competent weavers, they are eligible to take out loans to buy a loom. Thus far, 330 girls have received training in rug weaving and 175 girls have taken loans to buy looms. These girls get their orders for woven goods and raw materials from the center. They then complete the work at home and bring it to the center. They get paid as much as 120 pounds a month for this work. The cloth used to weave the rugs comes from fabric wholesalers who either donate waste cloth from clothing factories or sell it to the APE in bulk at low cost. There is no lower limit on how much girls must produce and, on average, most active girls earn about 100 pounds per month.

In order for a girl to work at home, she must have sufficient space for the loom and some assurance that her work will not be contaminated or soiled. Thus, it is not surprising that most of the girls who have taken out loans to buy looms are from non-garbage-collecting/sorting families. Girls coming from garbage-sorting families must either make arrangements to use looms belonging to non-garbage-collecting neighbors or they must reserve time to work on a loom in the training center.

In Maqattam today other girls are learning to do patchwork. They are taking loans to buy sewing machines or making arrangements to do their work at the center. Both programs have the flexibility to allow each girl who completes training to maintain and continue her incomegenerating work. The girls are paid not only for the volume of their work but for its quality, as well as for their observance of the basic rules of work organization. For example, girls who perpetually violate agreements on their hours may be docked small amounts of money as will girls who turn in work that is substandard.

A paper recycling and embroidery project was established by the APE in 1993 and may be the only project worldwide in which the recycling of paper is done exclusively by young women. Indeed, girls as young as twelve participate in this work. In total $63 e$ have been trained in paper recycling and the majority of them are active in the program on a weekly basis. In the last two years, the quality of paper the girls have produced has steadily improved as their knowledge and the technical facilities in which they work have been upgraded.

The economic terms of reference for girls in the paper-recycling project are slightly different from those in the rug-weaving and patchwork projects. After three months of training (the first two of which they receive no payment), these girls are formed into teams with each receiving a base 
salary of 70 pounds per month. Presently few girls are recruited and receive in-service training and are paid as regular workers. (Because training in paper recycling can be carried out alongside schooling--unlike weaving and sewing--and because there was such a demand for participation, girls in this program are not paid during their training period.) Team leaders chosen from among the girls are responsible for overseeing the production process from start to finish; they receive 90 pounds monthly. It is important to note that both the working conditions and the salary offered by the project are superior to the limited work opportunities available--sometimes illegally--for girls this age in other parts of Cairo. There girls work full-time in local sweat shops for between 70 and 80 Egyptian pounds per month without access to the literacy classes, tea breaks, or excursions that are part of the APE program.[10]

Paper recycling requires that a number of steps be carried out simultaneously by teams of girls. Between two and three teams are at work at the same time. Scrap paper is collected from schools and offices (separated by color and type before recycling) and then is shredded, soaked, and subsequently fed into a machine (called the Hollander Beater) which turns it into pulp. It is then treated with ingredients that assist the bonding of the paper thread, and poured, as an increasingly viscous liquid, into large tublike vats. Next, the mixture is scooped up into screened frames that resemble window screens allowing the fibers to catch and connect. While the paper is still wet, the girls turn over each screen and lay each piece of paper singly on a flat surface where it is dried and then, using weights, flattened.

Today, the recycled paper the girls produce is of sufficient quality to be used as writing and art paper. A heavier colored paper is also produced, which is cut into stand-up cards on which scenes of Egyptian life and other designs are embroidered. Now the paper recycling project can also produce marbleized paper gift bags of different sizes. As a next step, they hope to produce paper made from plant fibers and cotton materials that would produce a better quality paper that could be sold at a higher price to artists. In 1995, an exhibition of paintings and drawings on Maqattam paper by local artists was held with the help of CEDARE and Magid Farag, who hosted the exhibition in his open-air grounds on the Nile. The second exhibition was held a few months later at the Ramses Hilton Hotel.

The girls currently produce 61 square meters of paper per day and, in 1994 alone, almost 12,000 embroidered cards were sold. The rugs, patchwork, and paper are all sold in a Cairo shop made available by a board member of the APE, and the project regularly receives orders from charity bazaars and art supply shops throughout Egypt. Special orders have also been received from the United States and Europe.

\section{Money of Their Own and Pride in Themselves}

Despite their traditional economic contributions to their families, for most of the girls the money they receive from the Maqattam income-generating activities is the first they have ever earned themselves. Despite the fact that they pay the money directly to the girls, the project organizers had long been curious to know to what degree the girls are actually able to control this money themselves and how their families view their earnings. Therefore, in the summer of 1995, in-depth interviews were conducted with girls who had been in the program for several years.

Most of the young women reported their families respect that the money they earn is their own and do not appropriate it for other uses. Though some girls do decide to contribute some of this money to meet family needs, most hold the firm expectation (or have already had the experience) that the money is theirs to use as they see fit. Sometimes the girls use the money to purchase 
clothing, while others sometimes save the money to buy durable household items after they marry (as described below). Some mothers--clearly proud of their daughters' work and mindful of their challenging futures--emphasize that both their daughters' participation in the project and their earnings are "something for you."

All the project's activities in support of Maqattam's girls, whether conducted in the community or outside, are designed to instill discipline, pride, and tidiness: lining up to get on the bus, arriving on time for meals, gathering up waste in garbage bags. And, in keeping with the Egyptian love of celebration, many of these lessons are imparted through games and dance and impromptu plays and skits.

Several times a year, girls well-established in any of the production and social development programs are given an opportunity to take field trips outside their community. This may be a bus ride to a nearby lake or a visit to the pyramids. Then, once a year, the girls make a four-day visit to the Mediterranean Sea for a camping trip. In this environment they learn basic elements of hygiene, such as washing hands before and after meals, how to prevent lice, and how to use a latrine or flush a toilet (in some homes the pigsty still serves as the family toilet facility). These field trips also provide girls with a rare chance to see a world beyond Maqattam, not to mention giving them a chance to smell fresh air and providing a temporary escape from the realities of life in their communities.

\section{Community Health Care: A "Career" for Girls}

In 1981, a health study undertaken in the community by EQI revealed the following: Infant and under-five deaths in Maqattam were 240 per 1,000 as compared to 98 per 1,000 for all of Egypt, while causes of infant death were overwhelmingly related to tetanus (55 percent), dehydration (15 percent), malnutrition (10 percent), and measles (5 percent). Another, carried out in 1989, found that more than 50 percent of women in Maqattam were not receiving any prenatal care and only 32 percent were vaccinated against tetanus. Yet, in the same study, it was clear that the Maqattam citizens attached great value to their children's health; 80 percent reported going to private doctors when their children suffered from fever or diarrhea. In fact, the study revealed that the poorest garbage-collecting families often spent more money on doctors and medicine for their children than many better-off households.

At the same time that concern was rising in the community about general health practices, greater attention was also being focused on the connection between the unmet needs of adolescent girls and longer-term maternal and child health outcomes. Illiterate and disempowered mothers rarely receive adequate support during pregnancy, nor do they effectively attend to all the health needs of their infants and children. It was out of a commitment to change this situation that the Maqattam Community Health and Development Committee was formed.

The Health and Development Committee emerged formally in 1990 after a three-year process during which the APE board endeavored to provide support on an individual basis for staff working in a variety of women's programs. While the earlier one-to-one process had been successful in establishing trust within the community, by 1990 there was clearly a need for a formal committee structure. The Committee concentrates its efforts on staff and volunteers working on functional literacy, income-generating projects and training. 
Currently the Health and Development Committee meets at least once a month and has the enthusiastic participation of all those working on programs to assist women and children. In September 1993, the Committee agreed on a common definition of its mandate:

The Health and Development Committee seeks the cooperation of the associations in Maqattam working in the field of health and development with particular emphasis on women and girls to:

1. Constitute a forum for common reflection.

2. Learn about the priority needs of the people, particularly in the field of health and human development.

3. Support each other for the sake of increasing the effectiveness of the programs and projects undertaken by local organizations.

4. Increase the participation of young women and girls in decision-making.

The first major activity undertaken by the Committee was to develop a scheme to employ young women as health workers. In this way girls serving as agents of change to reach families with newborns and young children would, at the same time, be receiving knowledge of how to protect their own reproductive health. The decision to engage girls rather than older women as community health workers was based on the project's perception that many of the girls were truly eager to learn. As Marie Assaad, who chairs the Committee, puts it, "Girls have continuous demands for learning and knowledge about their reproductive health." Besides, older women were not only more often preoccupied but they tended to have more fixed ideas. Owing to the press of time or simply habit, they were considered more resistant to change.

The first community health program employing adolescent girls was established in 1988 and, through its household-visiting program, managed to increase childhood immunization levels in the community from 2 to 50 percent within one year. In 1995, these rates were close to 95 percent and, since 1989, there have been no child deaths due to tetanus.

From 1988 to 1993, the program operated according to its initial formula--succeeding waves of girls (sometimes as many as 20 a year) being trained as health visitors. These girls then moved around the community, bringing basic messages about maternal and child health and household hygiene as well as providing some services, such as administering first aid and providing home treatment of common ailments such as tonsillitis, colds, and diarrhea.

By 1993, however, the APE staff had started thinking about changing the project's design. This was because the earlier intervention, while addressing pregnant women and mothers of young children, had completely overlooked adolescent girls living in the same households. The project organizers, therefore, decided to add an "adolescent girls' initiative" to the project which would pay special attention to households with girls ages twelve to twenty. The resulting emphasis on linking girls together--the trained health visitors seeking out girls in other households --springs from the project's growing understanding that the window of age between twelve and twenty is the best time to reach the majority of girls as it is then that they begin to become engaged, if not married, with a large proportion becoming mothers.

This endeavor, entitled the Health Care of Families and Adolescent Girls Project, begins by selecting girls between the ages of twelve and eighteen from among the poorest families-typically garbage-collecting families. Before beginning their training, each girl is given a physical examination and laboratory tests; appropriate treatment is given for common conditions such as low hemoglobin and parasitic diseases (about two-thirds or more of the girls are afflicted). As virtually every girl in the community has a range of unattended health and nutritional problems, this process can take several months. 
Once all the girls are in good health themselves, training in primary and reproductive health care begins. The curriculum includes: household sanitation, nutrition, the sequence of childhood immunization, appropriate care during pregnancy, and strong messages discouraging female genital mutilation (FGM). While the girls are not paid any stipend during the training period, they are given useful items such as toothpaste, toothbrushes, soap, towels, first aid kits, and scissors as compensation for regular attendance and good work.

In Maqattam virtually all girls have been subjected to some form of female circumcision (Egyptians do not commonly use the international term female genital mutilation or FGM). While officially discouraged, this procedure is almost universally practiced among both Copts and Muslims. Yet, despite being circumcised themselves, the girls are quite willing--in fact sometimes enthusiastic--about carrying the anti-FGM message to the community, alongside all the other health messages. They have come to understand that FGM brings no benefit but rather can cause a good deal of harm to girls' and women's reproductive and sexual health, not to mention their psychological well-being.

The health visitors get three months of training and during this period receive no payment. By the third month of training, the girls are ready to make household visits, usually completing three or four each week. On these visits, the young health workers provide girls their own age and other family members with information about young women's health needs. They also impart basic knowledge about immunizations, proper nutrition, and hygiene, and present the argument against FGM. For this work they receive a salary of 70 pounds per month. Those who remain with the project for eight years are now earning 80 pounds per month for four afternoons of work per week.

\section{Great Expectations: Young Women Define Their Future}

Evaluating the success of a project such as this one, particularly in terms of empowerment goals, is obviously difficult. However, in the summer of 1994, a small experiment was undertaken. A group of girls participating in the Health and Development Project, as well as the APE's other income-generating activities, were interviewed. Included in the group were sixteen girls who had been involved in some aspect of the program for one year or more. All the girls participated in focus group discussions aimed to evoke their views about their own future reproductive health and personal fulfillment.

Not surprising in such a traditional community, the girls universally expect to marry, so this was taken as an entry point for discussion. What was detected in these in-depth group discussions was not changed expectations with regard to the inevitability of marriage, but rather changed expectations regarding the quality of their future lives, their role in selecting their husbands, the establishment of a more equitable basis for the husband and wife relationship, a clear desire to continue learning and earning after marriage, and a well-developed sense of their responsibility as future mothers - particularly with respect to daughters of their own. When the facilitators asked the girls to identify what they would like their future respective husbands to know about them that would make them "feel safe and valued," answers flowed almost immediately. At the conclusion of the session, the girls agreed to write letters to an imaginary future husband. Fourteen letters were completed and their lessons distilled into a single representative "Letter from Laila" addressed to their future husbands and their families. The girls said: 
1. "I should not get married before I am at least eighteen years old."

2. "I must get to know my future husband and he should know me. We need to agree on how to relate to each other, what kind of family we should have. We need to decide together on the size of our family, that girls are as valuable as boys and have a right to education and work just as much as boys."

3. "My husband should not blame me for giving birth to girls. He is the one responsible for that."

4. "Both of us must nurture our love and develop mutual respect for each other. He must know that women are not a burden to men and that women are not created solely for the pleasure of men."

5. "We must reject the harmful traditional practices such as the virginity test and the circumcision of young girls. He must fully understand the harmful effect of such practices as I have learned to understand them."

6. "We must together decide on the size of our family and what contraceptive method we should use.

7. "We girls have agreed together that we must have our first child during the first year of our marriage, and we would need to leave a space of two or three years before the birth of the second child. We know that for the sake of our health and the health of our children we should not have more than two or maximum three children."

8. "I would like my husband to encourage me to further my education and to continue with my work. I should not be solely responsible for the house chores, nor for the raising of our children; we must both share the joys and burdens of such work."

This letter will be posted on the wall of the community center once the new group of trainees discuss and modify the contents.

\section{The Boys' Response}

The letter was also read to a group of boys in a parallel focus group and these boys produced their own statements. Their views, while somewhat more traditional, still show some new perceptions and the evolving basis for more equal male-female partnerships in the coming generation. Though a distilled "Letter from Isaac" is still in the works, here is some of what young men of a similar age had to say. Out of eleven, nine boys agreed with the notion of educating girls equally with boys and the right of women to work outside the home. Ten out of the eleven rejected the virtually public "virginity test" conducted on the wedding night - in discussion they seemed to understand how it humiliates the bride and destroys the privacy of marriage. Ten out of the eleven also said they would not circumcise their daughters.

The development of these letters has proved to be an innovative means by which boys and girls in a conservative community can communicate by proxy. To the extent that these letters circulate in the community, they also allow for greater recognition of girls' reproductive rights, the education and work opportunities girls want and can clearly handle, and what the girls are seeking in terms of improved husband-wife relations. However, as we will see later, even when girls gain new skills and have less traditional values, if the families into which they marry (as well as their future husbands) still do not appreciate their competence or respect their rights, the personal autonomy they have gained through participation in the program may be lost. 


\section{Negotiating Girls' Right to Work and Gaining Respect for Their Time}

Mindful of the stress placed on poor families in general, specifically when social and economic change is rapid, the APE established a Crisis Management Committee aimed at finding and supporting Maqattam families in special need. The Crisis Management Committee is composed of two APE board members who oversee the health and literacy projects, along with another APE staff member, and a young woman from the community, who is responsible for coordinating their work. The Committee meets twice a month--more frequently should emergencies arise. Initially, the committee expected to deal primarily with financial crises, such as those that arise when a key family member dies or an accident befalls a child. However, they soon discovered that many of the crises brought to them actually revolved around the competing demands and expectations placed on girls and young women.

Frequently, the issue of girls' participation in the program (about two-thirds of the girls participating in the program are from garbage-collecting families) served to catalyze a time-use crisis both for the girl and her family. [11] But with the support of the Crisis Management Committee, even girls with fairly intense garbage-collecting and sorting responsibilities have been able to bargain with their families for the blocks of time they need to participate in the program-that is, with a few notable exceptions.

The story of Zahra (not her real name) provides a case in point. Zahra wanted to learn paper recycling, but her family opposed her participation because they relied intensely on the labor of this oldest female child. Over a period of several months, the Committee negotiated with the family to allow Zahra to be free by 9:00 AM (having risen at 4:00 AM to clean the pigsty and prepare the house for garbage sorting) so she could attend the paper-recycling program. However, after a few weeks, this arrangement fell apart because her father sometimes arrived late with the garbage, so Zahra was still sorting at 9:30 AM. At this point, the program compromised and set the official start time for Zahra at 9:30 AM.

The family also insisted that Zahra be home from "school" by 1:45 PM to prepare meals and get the house ready for the second round of garbage sorting. However, sometimes Zahra could not get home in time and then she would be harshly scolded. Another intervention with the family yielded an understanding that Zahra could not always get back before 2:00 PM.

Then Zahra showed an interest in participating in the adolescent health training program, which meets between 3:00 PM and 5:00 PM twice a week. She pressed her family to allow her to participate but, again, they were not in agreement. (Subsequently, social workers found out that Zahra was being beaten by her parents.) Finally, the head of the Crisis Management Committee visited Zahra's father one last time to attempt a compromise. In the end, both the father and mother agreed that twice a week their son (their youngest child who was fervently protected by the parents) would go out with the father on his afternoon garbage collection rounds thus freeing Zahra to join the health project.

This case, though exceptional in its intensity, illustrates a central issue. In the poorest communities, there is an inextricable link between the time use of adolescent girls and the work burdens of other family members. Often a girl, especially the oldest girl, is required to carry more responsibilities than the other children. In reality then, the Crisis Management Committee's negotiations, which were nominally about scheduling, were in fact negotiations over the family's view of this child. The Committee's intervention, and indeed the programs for girls themselves, have begun to individualize the girls--to define their rights and needs in contradistinction to the claims of the family. Through the structure imposed by the program, families have begun to 
regard a girl's time as both separate from and important to the family and to think ahead to the girl's longer term well-being and the ultimate value of the skills she may acquire.

In fact, what the Crisis Management Committee and the APE program as a whole are doing is negotiating the restructuring of what young girls do with their days, what places they are expected or allowed to be, with whom they can interact, and how they see themselves in relation to the wider world. The project has demonstrated that, with slight adjustments in "scheduling," a girl can suddenly move beyond the world of mother-father-sister- brother to one of studies, teachers, trainers, managers of income-generating programs, and the world beyond Maqattam--a whole new set of experiences and relationships beyond both family and the community.

\section{Negotiating Continuing Autonomy for Girls as They Marry}

Another kind of crisis regularly presented to the Committee, often in the disguise of monetary disputes within the family, emerged from the pressures surrounding the marriage of a daughter. On the one hand, families wish at all costs to avoid the social stigma and, to some extent, the material damage caused by having an unmarried daughter. On the other hand, with the cost of marriage rising all over Egypt, a girl's wedding has become at least a short-term financial hardship for most families. Even in the poorest communities families are expected to contribute household goods valued at as much as 3,000 pounds (approximately US $\$ 885$ ), which is equal to four months' income for a garbage-collecting family of six to eight members in Maqattam (and three months' salary for an average two-income working family in Egypt). For this reason, girls past menarche and approaching marriageable age find themselves the source of much family anxiety.

The Crisis Management Committee was concerned at several levels. First, despite the variety of social and economic measures already taken to empower girls ages twelve to twenty, the prevailing costs of marrying off daughters, along with the expectation that through marriage she (i.e., her labor and skills) will be lost to her natal family, leads to a devaluation of girls and, in some families, a view that they are a burden. Second, girls' fundamental sexual and reproductive rights are often violated. Girls are frequently coerced into marriages they do not choose and often at an age below that mandated by Egyptian law. Third, it has been found that early marriages cut girls off from prospects for future training and education even if they have been participants in the APE program for adolescents.

To encourage both delayed and voluntary marriages for young women, the Crisis Management Committee designed an innovative new program. A public announcement was made within the Maqattam community that 500 pounds (approximately US $\$ 148$ ) would be awarded to any girl in the community (who was affiliated with the program) who deferred her marriage until age eighteen and who freely consented to the marriage. To date, about forty-three girls have received this award.

To obtain the award, a girl approaches one of the Committee members with her request. Through indirect means, the Committee verifies her age (many girls do not have birth certificates) and the voluntary terms of her marriage. Further, before receiving the award, the girl must present a marriage certificate as, in a few cases, girls have tried to obtain the money based on an "engagement" to be married after their eighteenth birthday. 
The value of this bold program is now being reviewed. Over the summer of 1995, seven girls who had received the 500 pounds as newly-weds were interviewed about their experience. Their responses, alongside other demographic and social data available on 22 girls still living in the community who had received the 500 pounds over the last several years, were analyzed. Two-thirds of the girls who received the award were from garbage-collecting families and the majority married into garbage-collecting families. All of the girls interviewed indicated that they had used their money - not for a bedroom set, as originally posited by the program directors based on local custom - but for practical items such as a butagas (which reduces cooking time and increases the hygiene of food) and simple washing machines which are also time-savers with health benefits. The young women also reported that despite their lack of status within their husbands' homes, such items were clearly seen as their personal property, even when they lived-as most do-in an extended family household.

Some very troubling information also emerged in the course of these interviews. All of these girls had a median of two to three years participation in one of the APE's programs and thus had experienced several years of earning and saving independently. Yet, once married, their continued participation in income-generating work was often in doubt. Some of the young married women actually described their lives in their husbands' households as a setback and, in some cases, as virtual bondage.

In this traditional society, a new bride occupies the lowest rung in the domestic hierarchy, being subjugated to the wishes of her husband, her mother-in-law, and the wider family. In addition, once married, a young woman is expected to prove her fertility and consolidate her marriage by conceiving and bearing a child within the first two years. Yet, this obligatory and highly anticipated first pregnancy does not bring with it any leisure or preferential treatment for the young women; rather they reported that the excessive physical demands made on them did not abate and that no special consideration was given to their needs for better nutrition and rest. It is not surprising then that pregnant women in Maqattam are often malnourished and complain of general fatigue, and that the babies born to such young women tend to be weak and have low levels of immunity. Many of the young married women reported that their husbands felt it would reflect negatively on them in their role as providers if their wives worked to earn income. Even among the girls who had received the 500 pound award, two-thirds had dropped out of the program since getting married (and they were more likely to have dropped out if their husband was a garbage collector). A few reported that even the new social values they had adopted-such as the desire not to circumcise their daughters and a sense of equality between men and women-were under tremendous pressure during the first years of marriage. One young woman, who had participated in the program for almost seven years, reported being threatened that if she took up incomegenerating work again, she would be thrown out of the house.

To date, the combination of health and livelihood programs have succeeded in reaching an estimated one-sixth of all adolescent girls in the garbage-collecting community; theoretically all of these girls are not only eligible for the 500 pound award, but are eligible to continue their work in paper recycling, patchwork, and rug making after marriage. Yet, despite the delayed age of marriage and the desire for only two or three children, families still place a clear value on early pregnancy. The fact that a new bride has been earning on her own for some time does little to change her relatively low status in her husband's family. While the young brides who were interviewed indicated a desire to resist such challenges to their new ways of thinking, they recognized that, for the moment at least, they have been relegated to the traditional role of subservient wife who must obey the wishes of her mother-in-law and husband, in that order. Some spoke with longing of the moment when they would be able to form their own household and live apart, even if it were only one floor removed. Many indicated a desire not only to continue working, but to continue having contacts outside their home. 
So for most of these young women, the first few years of marriage represented a reversal in the development of their personal autonomy. This information, although discouraging, is vital to future program planning. As we will see, the project is now seeking ways to continue supporting the girls even though their status has changed from girls to young married women.

\section{Looking Ahead}

The APE's income-generating activities (the rug-weaving, patchwork, and paper recycling projects) are all under constant scrutiny with respect to their economic sustainability and the availability of viable markets for the products they produce. However, in terms of community acceptance, the ability of girls to master new skills, and the pleasure the young women take in their work and schooling opportunities, these projects are an unquestioned success.

With respect to the health work, the initial results of the girl-to-girl adolescent health program have led the organizers to try to replicate it in Tora, a smaller garbage-collecting community that is presently undergoing a comprehensive upgrading program. In Tora, the health work will begin with adolescent health workers reaching out to families in a neighboring community to begin to do an assessment of their knowledge levels and their willingness to be the focal point for community development efforts. The Maqattam experience of training adolescent girls in community health is thus serving as an effective model for Tora.

There are some other aspects of the program that perhaps need redesigning. It is still too early to evaluate the overall impact of the 500 pound program. To date, the forty-three girls who have received the award have been able to delay their marriages and have expressed delight in being able to secure equipment or goods that reduce their labor and improve their lives. Yet the receipt of such money, combined with participation in income-generating programs, has not immediately changed the lot of these new brides. These young women may potentially be freer than those who neither participated in the program nor received the money, but the project's organizers now see how much more needs to be done to assist them. The design of program strategies and the level of trust in the community developed by the Committee members have allowed the APE to negotiate the freedom to earn and learn for girls twelve to eighteen. The challenge is how to extend the approach to benefit young married women eighteen and older. How much more difficult will it be to gain the support and trust of a young woman's in- laws rather than her own parents? How can the program widen the horizon of a young woman who is no longer viewed as a growing daughter but an inexperienced wife and prospective mother?

A great deal of thought and consideration has been given to how best to support girls through the transition into marriage and early motherhood. As a first step, the Health and Development Committee has opened a nursery that currently cares for five infants and twenty toddlers. It is designed not only to provide employment opportunities and child care services within the community, but in particular to help support young mothers who wish to resume incomegenerating activities.

A second program, currently in the planning stages, will focus on men--youths, husbands, and fathers--and encourages their support of unmarried and married young women alike. The APE views this as critically important as it is concerned that there will be otherwise an increasing gap between the new and expanding aspirations of girls and young women and traditional male views of women's rights and responsibilities. The "Letter to Laila" and the "Letter from Isaac" exercises are just the beginning of what is hoped will be a longer process of community sensitization and public dialogue about the emerging roles of young women in Maqattam. So, quietly but resolutely, 
economic opportunities for girls are fomenting a revolution in Maqattam. The only question is, how far will it go?

\section{Lessons Learned}

1. Adolescent enterprise programs must recognize that at least two products are being simultaneously produced--services or products for sale and the building of human capital in the form of skills, decision-making capacity, and self-confidence. Girls' social and economic progress is closely linked. So while successful economic programs must be adapted to the realities of the society, at the same time they must also seek to change girls' social position. Organizers of economic programs for girls must, in many cases, retrieve girls' lost opportunities (as they have been heretofore excluded from learning and leadership roles) before preparing them for entry into the work place. This can be done by training them to meet schedules, present themselves attractively, produce work up to a certain quality, and work cooperatively with others.

2. Apart from offering an immediate economic benefit to girls from poor families, incomegenerating activities can serve as a means to "capture" them for introduction to a wider range of social possibilities, including basic education and training. Efforts to improve girls' livelihoods can and should be accompanied by improvements in other areas of their lives. In Maqattam, this includes changes in the community health environment and public discouragement of practices that deleteriously affect girls' self-esteem and physical well-being. Not only does the project promote a broad concept of community health by making garbage collecting and sorting more efficient and safer, but it also condemns traditions that are harmful either to the spirit or physical self of young women, such as female genital mutilation and forced and early marriage.

3. The key to making "outside" work opportunities for young girls desirable and acceptable requires that they be located in the community and operate in such a way that they do not compromise the girls' social status (i.e., potential marriageability) or unduly undermine the girls' vital work contributions to their families. Providing girls with organized earning opportunities away from home can be highly acceptable even to parents in poor, conservative communities. In Maqattam, once several cohorts of girls had received training and begun earning, the participation of daughters in these income-generating activities became so commonplace that parents no longer questioned their involvement; indeed, there are currently more girls and families that want to join the program than there are openings in the various programs.

4. Within the context of skills training and provision of income-earning opportunities, literacy is an essential tool; without this link, there is a direct cost to the enterprise in terms of the quality of work produced. In the case of the income-generating programs in Maqattam, a girl is not considered a full participant in any economic empowerment program unless she is either literate or is taking measures to become literate. Literacy classes operated by the project in turn use examples from the work place to make their points (i.e,. counting out squares and embroidering letters).

5. When appropriately trained, unmarried girls' advice about proper food, rest, pregnancy, and even family planning has proved to be acceptable and respected. The project has shown that adolescent girls can become effective community motivators by serving as paid providers of health information and services to families within their community, provided they have been well-trained and are perceived to be competent. After three months of training and apprenticeship, once they begin making home visits by themselves, the girls have proved to be effective agents in increasing the uptake of tetanus and other immunization as well as the adoption of good health practices for mothers and newborns. 
6. Maqattam girls as young as fourteen are quite capable of expressing a nontraditional set of values and setting out high expectations for their future marriages, including their rights and responsibilities as parents and workers. Given exposure to new work and social experiences, girls from highly traditional settings are able to articulate (and seek for themselves to varying degrees) a progressive vision of their future lives. Though the full impact of the intervention on their future lives remains to be seen, the girls attach a high value to education, training, income-generation, free choice of husbands in marriage, use of family planning, and avoidance of harmful traditional practices.

7. For some girls--often from the poorest families--their involvement in an incomegenerating or any enrichment program will require both ongoing negotiations with their families and flexibility on the part of program organizers. While there is apparently little tension in Maqattam over girls being able to keep their own earnings, the use of their time and the freedom to vary their schedules are often subjects of much contention. Some girls will need special support if they are to manage the conflicting demands of new skills training and earning opportunities and their family work commitments. In Maqattam, girls from garbage-collecting families have far more conflicts of this kind than girls whose families work in recycling and other related services. The willing ness of program organizers to negotiate with resistant parents is not only greatly appreciated by the girls themselves, but demonstrates to the rest of the community the extent to which these girls are valued.

8. The value of programs to improve the life skills, autonomy, and self-esteem of girls in Maqattam is severely undermined - at least temporarily - within the early years of the girls' marriages. Efforts to assist adolescent girls should not stop with their marriages, but must continue to help them through the early challenges of marriage and the birth of their first child. For the Maqattam project, an on-going challenge is finding avenues to assure a continuity of income-generating opportunities and social support to young brides during the very difficult years of their transition into a new and often oppressive family situation.

9. An important compliment to any program that seeks to reconfigure young girls' prospects are efforts to bring about new understandings of women's rights and practical support of these rights by men within the community. In the Maqattam community, there is a clear need, though not yet a clear plan, to interact with men of all ages--adolescents and adults--to broaden their traditional views of girls' and women's roles. Most critically, there appears to be a need to re-educate the community and revise its expectations of girls' behavior upon marriage. Reconfiguring the possibilities for girls and young married women is particularly challenging since to do so requires not just changing attitudes but redefining responsibilities within both partnerships and extended families so that men, and other family members, take on a larger and more fair share of the burden of caring for family members (young and old), household management, and, finally, livelihoods.

\section{Endnotes}

1. Peplinsky, Nancy L. 1994. Addressing Needs and Opportunities: A survey of programs for adolescents. (Washington, D.C.; International Center for Women).

2. Environmental Quality International. 1997. The Zabbaleen Environmental and Development Program Assessment. (Cairo: EQI).

3. For a comprehensive review of the range of community experiments in Maqattam, see Marie Assaad and Nadra Garas, "Experiments in Community Development in a Zabbaleen Settlement," in Cairo Papers in Social Science, vol. 16, monograph 4 (American University of Cairo Press, Winter 1993/94).

4. Kamel, Laila Iskandar. 1994. Maqattam Garbage Village, Cairo, Egypt. (Heliopolis, Cairo, Egypt, Stallion Graphics, p. 6.) 
5. Khattab, Hind. 1996, "Women's Perceptions of Sexuality in Rural Giza," Monographs in Reproductive Health No. 1. (The Population Council, Cairo, Egypt

6. Baseline studies of girls' health are reported upon in the project submission made by the APE, "The Health Care of Families and Adolescent Girls in the Zabbaleen area of Maqattam." 1995. APE, Cairo, Egypt.

7. Environmental Quality International. 1997.

8. Environmental Quality International. 1997.

9. Kamel. Maqattam Garbage Village, Cairo, Egypt. This text is particularly helpful in getting a sense of selection criteria for trainees and the social transformations that the training and income-generation bring about.

10. For female youth under fifteen, the average wage in 1992 was 76 pounds per month. Source: CAPMAS. 1992. Employment, wages and hours of work. However, it is also important to note that those girls living in equally poor families not involved in garbage collection in Maqattam actually may have time on their hands; in interviews, some described their lives before marriage as "waiting around." 